\title{
AXL and MET receptor tyrosine kinases are essential for lung cancer metastasis
}

\author{
YUN JUNG CHOI ${ }^{1}$, JI HYE KIM ${ }^{5}$, JIN KYUNG RHO ${ }^{1,2}$, JOONG SUN KIM ${ }^{6}$, CHANG-MIN CHOI $^{3}$, \\ WOO SUNG KIM ${ }^{4}$, JAEKYOUNG SON ${ }^{5}$ and JAE CHEOL LEE ${ }^{3}$ \\ ${ }^{1}$ Asan Institute for Life Sciences, Departments of ${ }^{2}$ Convergence Medicine, ${ }^{3}$ Oncology and \\ ${ }^{4}$ Pulmonology and Critical Care Medicine, Asan Medical Center, ${ }^{5}$ Department of Biomedical Sciences, \\ College of Medicine, University of Ulsan, Seoul 138-736; ${ }^{6}$ Dongnam Institute of Radiological \\ and Medical Sciences (DIRAMS), Busan 619-953, Republic of Korea
}

Received September 27, 2016; Accepted February 9, 2017

DOI: $10.3892 /$ or.2017.5482

\begin{abstract}
The AXL and MET receptors regulate key processes in tumor growth, metastasis, and drug resistance; thus, they have recently been implicated as promising therapeutic targets in various tumors. We investigated the metastatic potential and crosstalk between these receptors in non-small cell lung cancer (NSCLC). We found that the treatment of NSCLC cells with hepatocyte growth factor (HGF) and growth arrest-specific 6 (Gas6), as ligands for MET and AXL, respectively, promoted their migration and invasion ability. However, treatment with inhibitors of each of these receptors significantly reduced the migratory and invasiveness of the cells, although their inhibitory rates varied according to the inhibition of each receptor. In addition, the suppression of each receptor by shRNA resulted in reduced migration and invasiveness. Notably, the suppression of AXL was more effective than the suppression of MET in the inhibition of migration and invasion. In accordance with in vitro results, when the cells were transferred via tail vein injection, AXL inhibition was more efficient in attenuating metastasis than MET inhibition. Clinically, AXL or MET expression is associated with a poor prognosis in primary tumors of NSCLC. In summary, AXL and MET can regulate tumor metastasis, but AXL was shown to be more potent than MET in lung metastasis. Thus, we conclude that AXL might be a suitable therapeutic target for the inhibition of lung metastasis.
\end{abstract}

Correspondence to: Dr Jaekyoung Son, Department of Biomedical Sciences, College of Medicine, University of Ulsan, Seoul 138-736, Republic of Korea

E-mail: jaekson@amc.seoul.kr

Dr Jae Cheol Lee, Department of Oncology, Asan Medical Center, College of Medicine, University of Ulsan, Seoul 138-736, Republic of Korea

E-mail: jclee@amc.seoul.kr

Key words: receptor tyrosine kinases, lung metastasis, therapeutic target

\section{Introduction}

The receptor tyrosine kinases (RTKs) are part of the larger family of protein tyrosine kinases that relay signals from extracellular growth factors into the cells $(1,2)$. They regulate many essential cellular processes in mammalian development and adult tissue homeostasis. However, although RTKs are critical in maintaining normal physiology, dysregulation of certain RTKs has been implicated during the development and progression of several types of cancer (3).

AXL is a member of the Tyro2-Axl-Mer (TAM) RTK subfamily $(4,5)$, and is activated by the vitamin $\mathrm{K}$-dependent protein product of the growth arrest-specific gene 6(Gas6) $(6,7)$. The biological function of AXL/Gas6 signaling is associated with cell growth and survival in normal and cancer cells (8). AXL overexpression and signaling, in particular, has been implicated in progression of cancers such as glioma, melanoma, and colon, breast, gastric, and lung cancer (9-14). Some reports have demonstrated that AXL overexpression is correlated with poor prognosis in several cancers (15-17). It has also been suggested that AXL regulates metastasis in various cancer types (18-20). Our previous studies, along with recent findings, have reported that AXL mediates cancer cell resistance to multiple targeted agents such as $\operatorname{ALK}(21)$, EGFR $(22,23)$, or BRAF inhibitors (24). Thus, AXL has now been recognized as a potential therapeutic target in various tumors.

The MET proto-oncogene encodes for the RTK c-MET, which is also known as hepatocyte growth factor receptor. Various cells widely express MET, where it is essential for embryonic development $(15,25)$ and tissue repair $(26,27)$. MET is activated by a single ligand, termed either hepatocyte growth factor (HGF) or scatter factor. In cancer cells, aberrant signaling of MET may occur via various mechanisms such as gene amplification, overexpression, mutations, increased autocrine or paracrine ligand-mediated stimulation, and interaction with another cell-surface receptor. In addition, a number of studies have demonstrated that MET is overexpressed in several types of cancers, including lung, breast, ovary, kidney, colon, thyroid, and liver cancer. Aberrant activation of MET under any pathological condition can confer proliferative, survival, and metastatic abilities on cancer cells (28-34). Thus, 
along with AXL, MET is also a potential biomarker and therapeutic target in cancer therapy.

Our previous studies have shown that AXL and MET are associated with acquired resistance to EGFR tyrosine kinase inhibitors (TKIs) $(23,32)$. In fact, many studies have demonstrated that each of these two receptors is associated with chemoresistance, metastasis, cell proliferation and survival, and poor survival in patients with non-small cell lung cancer (NSCLC) (14,33-36). Salian-Mehta et al first demonstrated that crosstalk between AXL and MET promotes neuronal cell migration and survival through gonadotropin releasing hormone (37). However, the possibility of crosstalk between AXL and MET in cancer cells, and the role of their interaction in cancer progression, is still unknown. The aim of this study was to evaluate the potential role of AXL and MET in lung metastasis, and investigate their association with patient outcomes.

\section{Materials and methods}

Cell culture and reagents. The human NSCLC cell lines A549, H2009, and Calu-1 were obtained from the American Type Culture Collection (Rockville, MD, USA). The cells were cultured in RPMI-1640 medium supplemented with $10 \%$ fetal bovine serum, $100 \mathrm{U} / \mathrm{ml}$ penicillin, and $100 \mu \mathrm{g} / \mathrm{ml}$ streptomycin (Life Technologies, Carlsbad, CA, USA) at $37^{\circ} \mathrm{C}$ in humidified air containing $5 \% \mathrm{CO}_{2}$. HGF and Gas6 were purchased from Sigma-Aldrich (St. Louis, MO, USA). PHA665752 and XL880 were purchased from Selleck Chemicals (Houston, TX, USA).

MTT assay. Cells were seeded in 96-well sterile plastic plates overnight and then treated with drugs. After $72 \mathrm{~h}, 15 \mu \mathrm{l}$ of MTT solution $(5 \mathrm{mg} / \mathrm{ml})$ was added to each well and the plates were incubated for $4 \mathrm{~h}$. Crystalline formazan was solubilized with $100 \mu 1$ of a $10 \%$ (w/v) SDS solution for $24 \mathrm{~h}$, and then absorbance at $595 \mathrm{~nm}$ was read spectrophotometrically using a microplate reader. The results are representative of at least three, independent experiments, and the error bars signify standard deviations (SDs).

Western blot analysis. The cells were lysed in EBC buffer containing $50 \mathrm{mM}$ Tris- $\mathrm{HCl}(\mathrm{pH} 8.0), 120 \mathrm{mM} \mathrm{NaCl}$, $1 \%$ Triton X-100, 1 mM EDTA, $1 \mathrm{mM}$ EGTA, $0.3 \mathrm{mM}$ phenylmethylsulfonyl fluoride, $0.2 \mathrm{mM}$ sodium orthovanadate, $0.5 \% \mathrm{NP}-40$, and $5 \mathrm{U} / \mathrm{ml}$ aprotinin. To evaluate the interaction of AXL and MET, lysates were immunoprecipitaed with an anti-AXL or MET antibody. Antibodies specific for p-EGFR (Tyr1173), EGFR, MET, and $\beta$-actin were obtained from Santa Cruz Biotechnology (Santa Cruz, CA, USA), and antibodies specific for p-MET (Tyr1234/1235) and p-AXL (Tyr702) were purchased from Cell Signaling Technology (Beverly, MA, USA). Proteins were detected by the enhanced chemiluminescence system (Thermo Scientific, Rockford, IL, USA) according to the manufacturer's instructions.

Migration and invasion assays. Migration and invasion assays were performed according to a previously described method (38). Results are representative of at least three independent experiments, and migrated or invaded cells were counted under a microscope. Results were expressed as means \pm standard deviations.

Lentivirus-mediated shRNA infection. The RNAi Consortium clone IDs for the shRNAs used in this study are as follows: TRCN0000194971 (shAXL) and TRCN0000196685 (shMET). For lentiviral infection, the cells were infected with shControl, shAXL, or shMET lentivirus. To validate the migration and invasion ability, the cells were infected with shControl, shAXL, or shMET for $48 \mathrm{~h}$, and then treated with $2 \mu \mathrm{g} / \mathrm{ml}$ puromycin for $72 \mathrm{~h}$. The suppression of each protein was confirmed by western blotting before performing the migration and invasion assay.

In vivo studies. All animal studies were conducted following a protocol approved by the Institutional Animal Care and Use Committee of the Dongnam Institute of Radiological and Medical Sciences. BALB/c nude mice (male, 18-20 g, 6-week old) were purchased form SLC Co. (Shizuoka, Japan). All experiments used 5 mice per group. Cells $\left(1 \times 10^{6}\right)$ stably expressing control, AXL, or MET shRNA were suspended in $100 \mu 1$ serum-free RPMI-1640 medium, and injected into the tail vein or the right flank of mice. After 21 days, lung metastasis was determined by examining serial sections of every lung tissue block by microscopy, and tumor of the right flank of mice were extracted and weighed.

Patient and study design. For this retrospective study, a total of 126 patients were recruited from the Asan Medical Center. All patients underwent curative resection for NSCLC between January 2006 and December 2010 and were diagnosed with stage II (the American Joint Committee on Cancer seventh edition). All participants had adequate tumor specimens for immunohistochemial staining and detailed prognosis records. Patients with other primary cancers that could affect survival were excluded. Patients who died of perioperative complications within 3 months of surgery were also excluded. Clinical, pathological, and radiological data were retrospectively reviewed, as well as the follow-up information obtained until December 2013. Tumor recurrences were assessed by computed tomography, magnetic resonance imaging, or bone scans. The primary endpoint was to assess whether the expression of AXL and MET affected survival in terms of disease-free survival (DFS). DFS was defined as the time from resection to locoregional or distant recurrences or death from any cause (whichever was earlier). The institutional review board approved this study protocol.

Immunohistochemical staining of AXL and MET and analysis of AXL and MET expression. Paraffin-embedded tumor samples were collected from the patients and deparaffinized. After rehydration in alcohol, immunohistochemical staining for AXL and MET was performed using the anti-AXL antibody (Santa Cruz Biotechnology) and the anti-MET antibody (Ventana Medical Systems, Tucson, AZ, USA), respectively. Immunohistochemical analyses were evaluated at the Asan Medical Center. The expression levels of AXL and MET were scored semiquantitatively according to standard protocols. The percentage of positively stained tumor cells was scored as follows: $0(<5 \%), 1(5-25 \%), 2(25-50 \%)$, or $3(>50 \%)$. The 

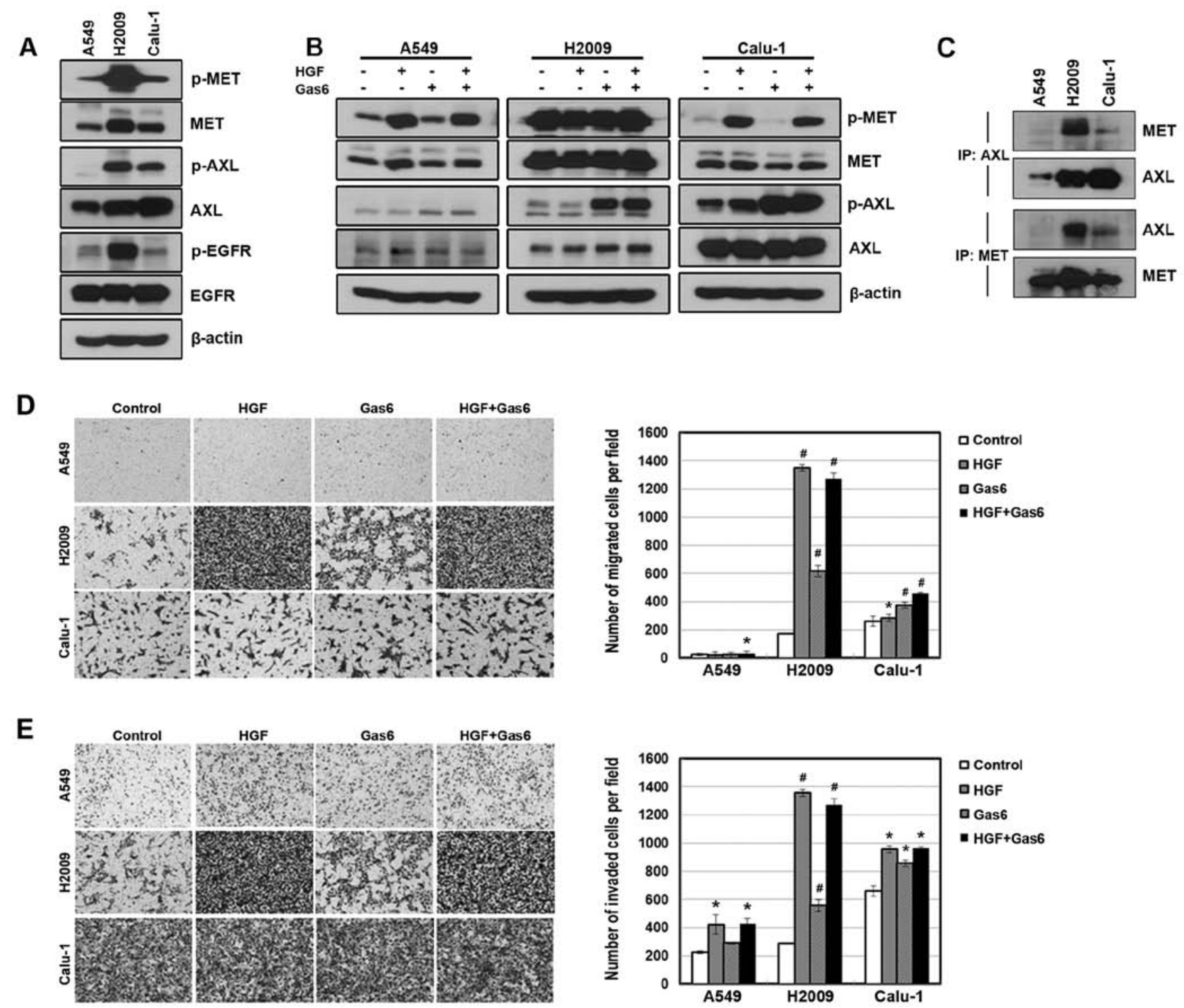

Figure 1. Treatment of ligands with AXL and MET promotes migration and invasion of NSCLC cells. (A) The basal expression of AXL and MET was determined by western blotting. (B) After serum starvation, cells were treated with $400 \mathrm{ng} / \mathrm{ml} \mathrm{Gas} 6$ or $50 \mathrm{ng} / \mathrm{ml} \mathrm{HGF}$ for 10 min. The AXL and MET activation was detected by western blotting. (C) Whole-cell extracts from NSCLC cells were immunoprecipitated with anti-AXL or anti-MET. The immunoprecipitates were subjected to western blot analysis with the indicated antibodies. (D and E) Cells were seeded onto either collagen or Matrigel-coated polycarbonate filters to determine their migratory and invasive potentials, respectively. Cells were incubated in modified Boyden chambers with $400 \mathrm{ng} / \mathrm{ml} \mathrm{Gas} 6 \mathrm{or} 50 \mathrm{ng} / \mathrm{ml} \mathrm{HGF}$ for $12 \mathrm{~h}$, and the cells that penetrated the filter were stained and counted using a light microscope. Error bars represent standard deviations. ${ }^{*} \mathrm{P}<0.1$ and ${ }^{~} \mathrm{P}<0.001$ in comparison with control cells.

staining intensity was scored as follows: 0 (no staining), 1 (weakly stained), 2 (moderately stained), or 3 (strongly stained). Based on the immunohistochemical staining scores, which were obtained by adding the positive proportion scores to the intensity scores, the tumors were classified into negative tumors (score 0-3) and positive tumors (score 4-6).

Statistical analysis. The Kruskal-Wallis test was performed for statistical analysis (for continuous variables), and the Chi-square test or Fisher's exact test was performed for categorical variables. Survival rates were estimated by the Kaplan-Meier method and compared by the log-rank test. All $\mathrm{P}$-values reported were the result of two-sided tests, and values $<0.01$ were considered statistically significant. All statistical analyses were performed with SAS software, version 9.4 (SAS Institute, Inc., Cary, NC, USA).

\section{Results}

Activation of AXL and MET receptor promotes migration and invasion of NSCLC cells. We have previously demonstrated that the expression of AXL and MET is associated with acquired resistance to EGFR-TKIs $(23,32)$. In addition, these receptors have been recently referred to as biomarkers that predict poor prognosis of various tumors (15-17,28-30). Thus, we investigated whether AXL and MET signaling affects the cellular mobility of NSCLC cells. We found that AXL and MET were expressed or activated in three NSCLC cell lines, although the expression and activation of these receptors was more or less cell line-dependent (Fig. 1A). Treatment of the cells with ligands to each receptor increased the activity of the receptors (Fig. 1B). In addition, AXL receptors interacted with MET receptors at basal level of endogenous proteins, 
A
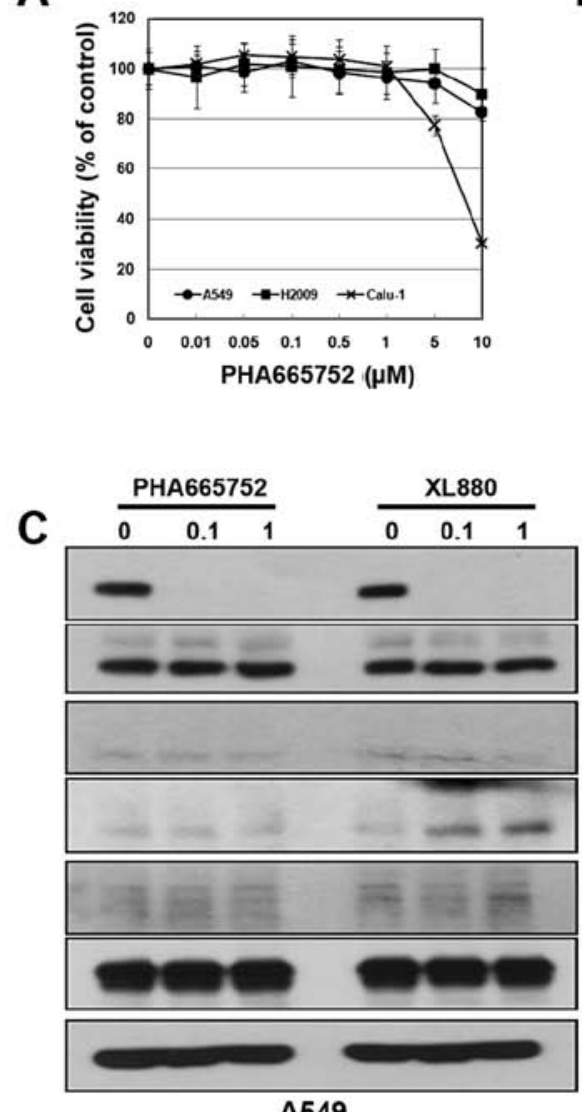

A549
B

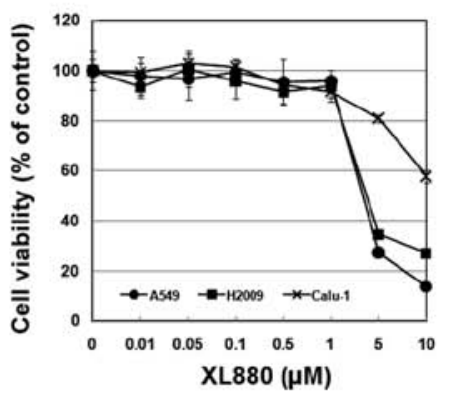

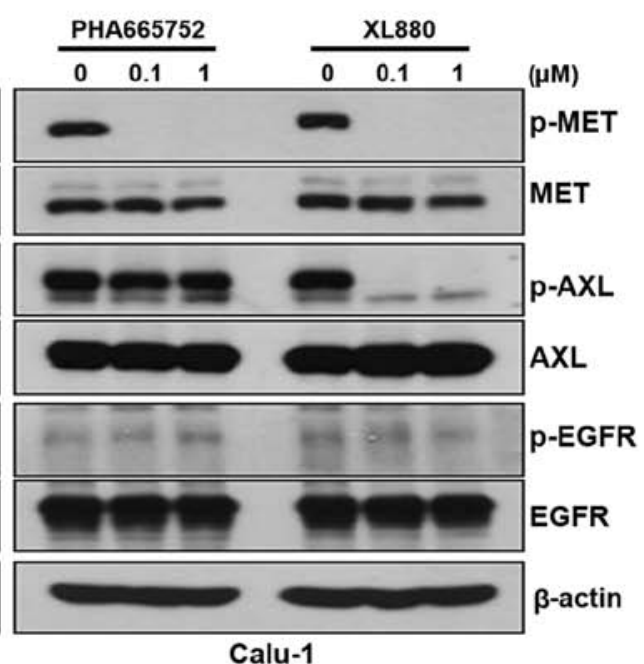

Calu-1

D
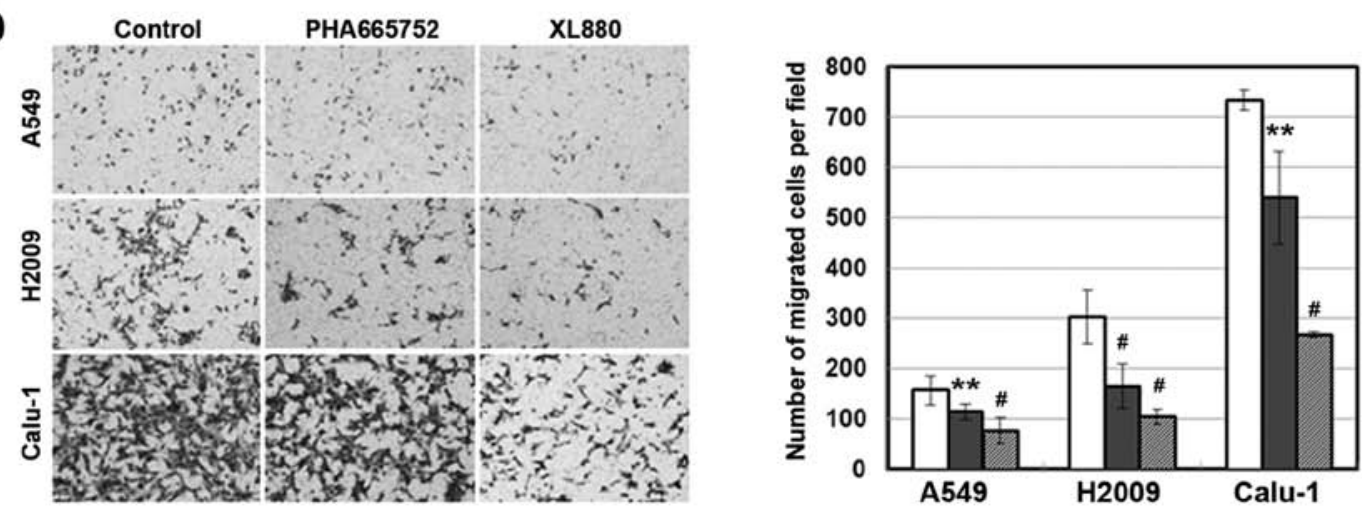

$\square$ Control

口 PHA665752

a XL880

E
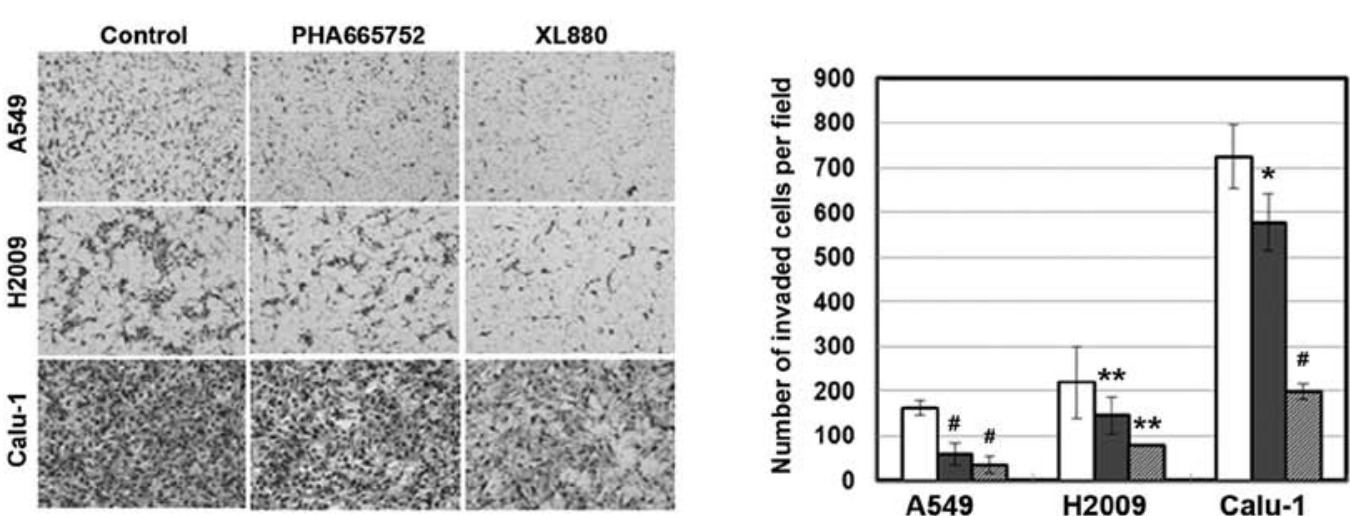

$\square$ Control

口 PHA665752

- XL880

Figure 2. Inhibition of AXL and MET activity reduces migration and invasion of NSCLC cells. (A and B) Cells were treated with PHA665752 or XL880, and drug sensitivity was determined by MTT assay. (C) Cells were treated with the indicated doses of PHA665752 and XL880 for $24 \mathrm{~h}$. Inhibition of AXL and MET activity were determined by western blotting. (D and E) Cells were treated with $1 \mu \mathrm{M}$ PHA665752 or $1 \mu \mathrm{M} \mathrm{XL880} \mathrm{and} \mathrm{experiments} \mathrm{were} \mathrm{performed} \mathrm{as}$ in Fig. $1 \mathrm{C}$ and $\mathrm{D} .{ }^{*} \mathrm{P}<0.1,{ }^{* *} \mathrm{P}<0.01$, and ${ }^{*} \mathrm{P}<0.001$ in comparison with control cells. 


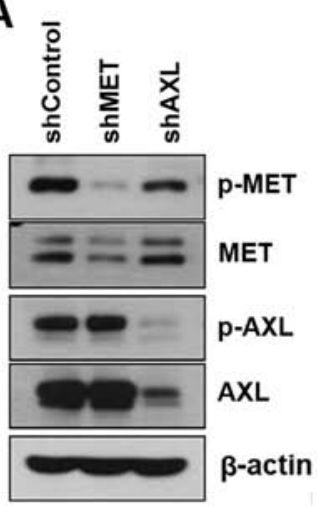

B

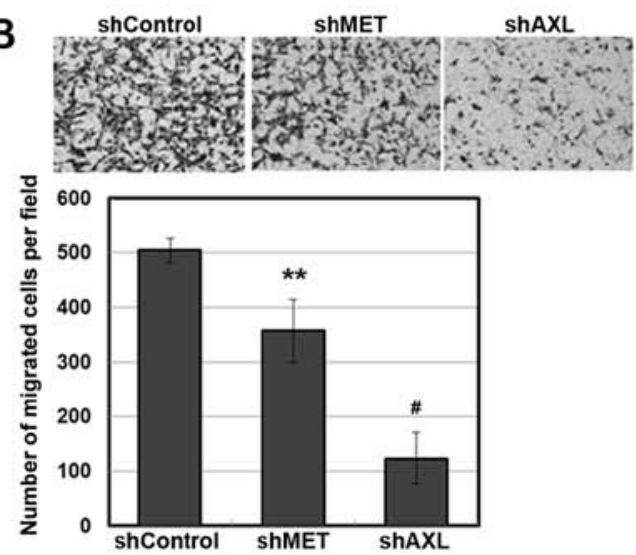

C

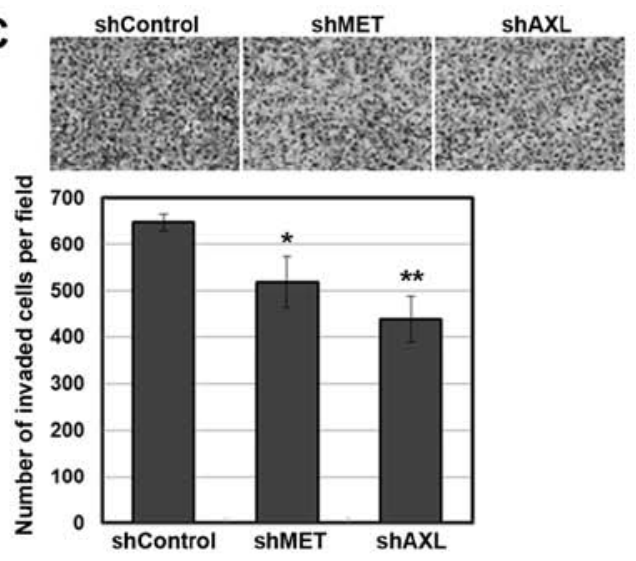

Figure 3. Suppression of AXL and MET expression reduces migration and invasion of Calu-1 cells. (A) Lentiviral constructs containing AXL and MET shRNAs were infected into Calu-1 cells, and suppression of each protein was confirmed by western blot analysis. (B and C) After the infection of lentiviral shRNAs of AXL and MET, cells were selected with $2 \mu \mathrm{g} / \mathrm{ml}$ puromycin and analyzed by migration and invasion assays, as described in Fig. $1 \mathrm{C}$ and $\mathrm{D}$. ${ }^{*} \mathrm{P}<0.1$, ${ }^{* *} \mathrm{P}<0.01$, and ${ }^{\#} \mathrm{P}<0.001$ in comparison with control cells.

although the interaction of the receptors was weak in A549 cells (Fig. 1C). Consistent with this observation, ligand treatment significantly enhanced the migration and invasiveness of the cells (Fig. 1D and E). However, the combined treatment of the ligands did not show a synergistic effect on the migratory and invasive abilities.

To further investigate the relationship between AXL or MET signaling and cellular mobility, we treated the cells with inhibitors of each receptor. We used the PHA665752 and XL880 as a selective inhibitor of MET and AXL, respectively. Although XL880 did not show selectivity to the AXL receptor, both the inhibitors effectively inhibited the activity of their corresponding receptors (Fig. 2C). In addition, cellular toxicity was not revealed until inhibitor concentrations were $1 \mu \mathrm{M}$ or higher (Fig. 2A and B). We found that the inhibition of AXL or MET resulted in reduced migration and invasiveness (Fig. 2D and E). Notably, XL880 treatment was more effective in the inhibition of cellular mobility than PHA665752 treatment.

AXL signaling is more potent than MET in inhibition of metastasis. To further evaluate the role of AXL and MET in metastasis, we used an shRNA against each receptor. Calu-1 cells were infected with AXL or MET-specific shRNA lentiviral particles, which substantially suppressed the amount and activity of each receptor, as determined by western blotting (Fig. 3A). As a consequence, the suppression of AXL or MET resulted in reduced migratory and invasive capabilities (Fig. 3B and C). Notably, the suppression of AXL was more effective in the inhibition of cellular mobility than the suppression of MET $(\mathrm{P}=0.00034$ and $\mathrm{P}=0.00032$ for $\mathrm{AXL}$ shRNA versus MET shRNA, in migration assay and invasion assay, respectively).

To determine whether AXL and MET play a key role in the regulation of lung colonization and metastasis, we downregulated the AXL and MET expression in Calu-1 cells using shRNA before implantation in the tail vein injections, and then examined the lung weight and number of tumor nodules, respectively. As shown in Fig. 4, knockdown of AXL or MET significantly reduced the lung tumor colonization and lung weight. Consistent with in vitro studies, AXL knockdown yielded a significantly higher relative inhibition of metastasis than MET knockdown $(\mathrm{P}=0.012$ and $\mathrm{P}=0.035$ for $\mathrm{AXL}$ shRNA versus MET shRNA, in lung weight and number of tumor nodules, respectively). In addition, the suppression of AXL or MET significantly reduced the tumor cell proliferation (Fig. 4D). Taken together, the results indicate that AXL and MET signaling are associated with cellular mobility and metastasis as well as proliferation in lung cancer, but AXL inhibition might exhibit higher efficacy in blocking metastasis than MET inhibition.

Clinical significance of AXL and MET expression in NSCLC cells. A total of 126 patients with surgically resected NSCLC were analyzed. The median patient age was 63 years (range, 56-69 years). Of the 126 patients, 26 (20.6\%) were female. All the patients had stage II lung cancer. Regarding histological tumor types, 53 patients $(42.1 \%)$ had adenocarcinoma and 73 (57.9\%) had squamous cell carcinoma.

As shown in Fig. 5A, of the 126 patients, 34 (27.0\%) had AXL-positive tumors and $9(5.6 \%)$ had MET-positive tumors. The 1- and 2-year DFS rates for AXL-positive patients were 97.1 and $71.3 \%$, respectively; and for MET-positive patients, were 63.5 and $47.6 \%$, respectively. DFS was significantly shorter in the AXL-positive group than in the negative group (2-year DFS rate 71.3 vs $85.8 \%, \mathrm{P}=0.003$, Fig. 5B). In addition, DFS was significantly shorter in the MET-positive group than in the negative group (2-year DFS rate 47.6 vs $85.8 \%, \mathrm{P}<0.001$, Fig. 5B).

\section{Discussion}

Although AXL and MET have recently been associated with acquired resistance to anticancer drugs, they are well known for their roles in tumor progression, such as those in development, survival and metastasis (5,39-41). However, crosstalk between AXL and MET in tumor progression remains unclear. In general, the interaction between RTKs and nonRTKs, or self-assembly of homodimers or heterodimers, plays an important role in cellular signaling. This interaction is mediated in a ligand-dependent or -independent manner. 
A

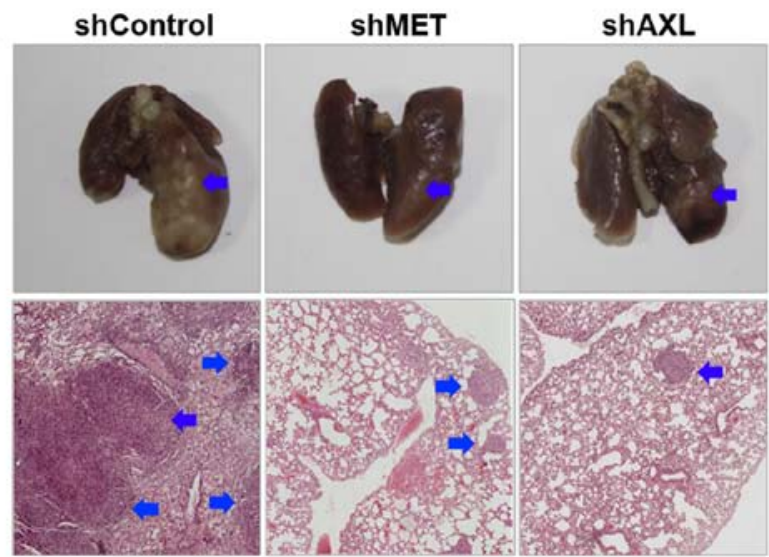

C

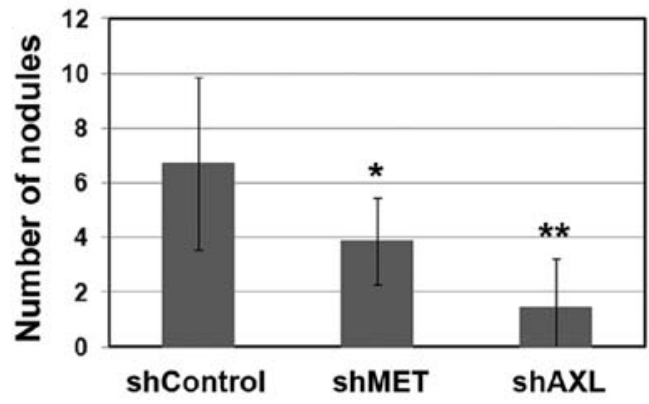

B
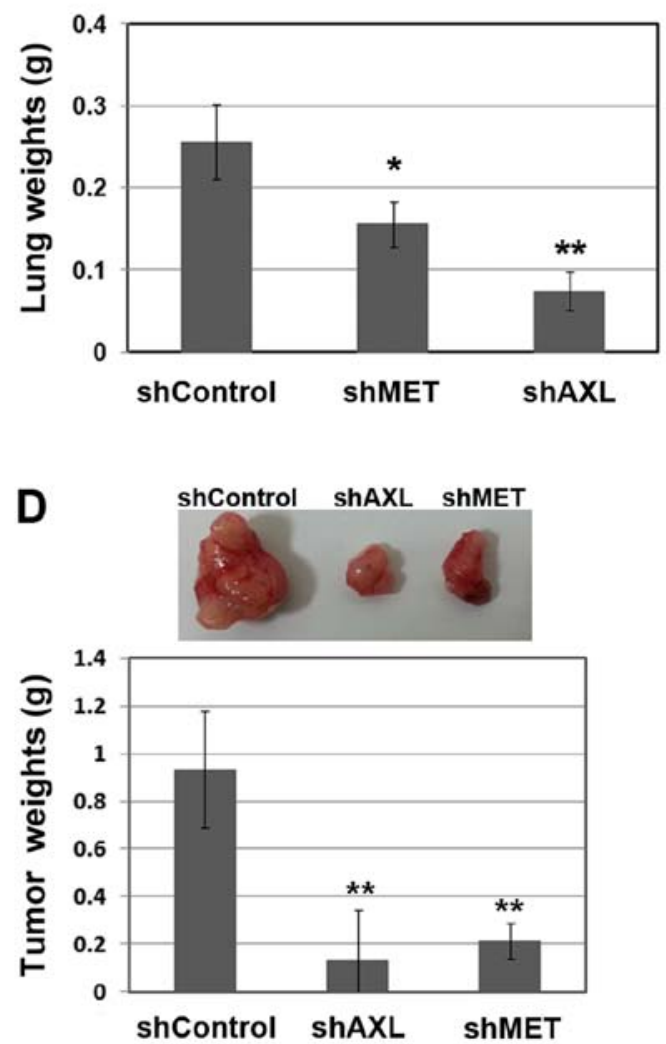

Figure 4. Suppression of AXL and MET expression reduces lung metastasis. Calu-1 cells with downregulated AXL or MET expression were inoculated via mice tail vein. Mice were sacrificed at day 21. (A) The lung was captured and stained with hematoxylin and eosin (x200 magnification), (B) weighed, and (C) the metastatic nodules were counted. The blue arrows indicate the metastatic nodules. (D) Calu-1 cells with downregulated AXL or MET expression were subcutaneously injected into the right flank of the mice. Mice were sacrificed at day 21 . The tumor was captured and weighed. ${ }^{*}<0.1$ and ${ }^{* *} \mathrm{P}<0.01$ in comparison with control group.

A

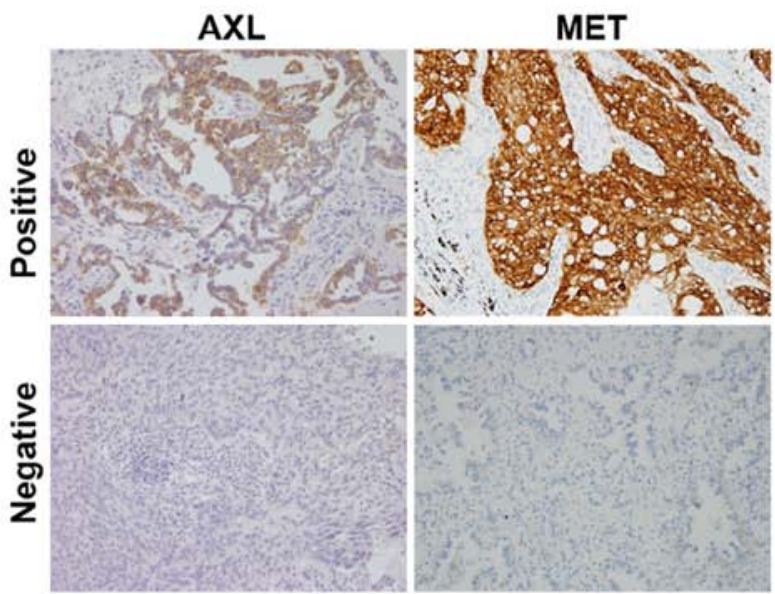

B

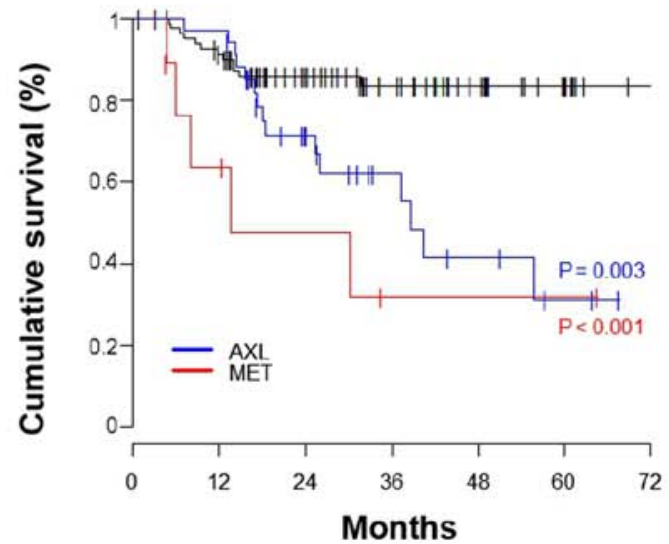

Figure 5. Immunohistochemical staining of NSCLC tissues for AXL and MET. (A) Representative images (x200 magnification) of immunohistochemical staining for AXL and MET in NSCLC tissues. (B) Kaplan-Meier estimates of the probability of survival. DFS rates for AXL andMET expression in NSCLC patients are shown.

In this study, we found that HGF-dependent MET activation enhanced the AXL activity in Calu-1 cells, but not in the other cells. However, all cells showed interaction of both AXL and MET at endogenous levels. Previous studies have demonstrated the physical interaction of AXL and MET by co-immunoprecipitation under conditions of ectopic expression (42). Notably, we found that AXL knockdown decreased the MET activity without reduction of MET expression. AXL and MET signaling share similar downstream molecules such as PI3K and Akt. Thus, a better understanding of crosstalk 
between AXL and MET is needed to evaluate their roles in tumor progression.

Many reports have suggested that both AXL and MET contribute to metastasis in many types of cancer $(3,5,10,20$, 36,39-41). We showed that Gas6 or HGF treatment enhanced the migration and invasiveness of the cells, whereas the inhibitors of each receptor decreased these properties. We used the PHA66572 and XL880 to inhibit the activity of MET and AXL, respectively. However, XL880 treatment was more potent than PHA665752 treatment in the inhibition of the migratory and invasive abilities. The difference in inhibitory rates may result from that fact that XL880 is a multi-kinase inhibitor, and inhibits AXL as well as MET. In addition, AXL knockdown was found to be more effective than MET knockdown in the inhibition of cellular mobility in vitro and lung metastasis in vivo. This might have resulted from crosstalk between AXL and MET, wherein AXL knockdown leads to inhibition of MET activity.

The essential steps required for tumor metastasis include penetration of tumor cells into the blood or lymphatic vessels, circulation through the intravascular stream, and proliferation at another site (43). AXL and MET signaling promote cellular proliferation in normal as well as tumor cells. Thus, they can play an important role when tumor cells proliferate at another site. Our results showed that the suppression of AXL and MET reduced tumor cell proliferation. Consistent with the results of metastasis, tumor cell proliferation was remarkably decreased upon suppression of AXL as compared with that upon suppression of MET. These results suggested that AXL is more effective than MET in regulating the inhibition of lung metastasis.

Consistent with our results, previous data have shown that high AXL or MET expression is an adverse prognostic factor (44-48). In our data, DFS was remarkably shorter in MET-positive patients than in AXL-positive patients during the early periods, but there was no significant difference between the two groups after 4 years. Owing to the small number of double-positive patients, the DFS of both AXLand MET-positive patients could not be evaluated. Thus, more clinical samples are needed to investigate crosstalk between AXL and MET.

In conclusion, AXL and MET are associated with cell proliferation and metastasis in lung cancer, and the crosstalk between these receptors affects tumor progression.

\section{Acknowledgements}

This study was supported by the Basic Science Research Program through the National Research Foundation of Korea (NRF, grant 2014R1A2A2A01003200438 to J.C.L.).

\section{References}

1. Robinson DR, Wu YM and Lin SF: The protein tyrosine kinase family of the human genome. Oncogene 19: 5548-5557, 2000.

2. Schlessinger J: Cell signaling by receptor tyrosine kinases. Cell 103: 211-225, 2000.

3. Krause DS and Van Etten RA: Tyrosine kinases as targets for cancer therapy. N Engl J Med 353: 172-187, 2005.

4. Hafizi S and Dahlbäck B: Signalling and functional diversity within the Axl subfamily of receptor tyrosine kinases. Cytokine Growth Factor Rev 17: 295-304, 2006.
5. Linger RM, Keating AK, Earp HS and Graham DK: TAM receptor tyrosine kinases: Biologic functions, signaling, and potential therapeutic targeting in human cancer. Adv Cancer Res 100: 35-83, 2008.

6. Manfioletti G, Brancolini C, Avanzi G and Schneider C: The protein encoded by a growth arrest-specific gene (gas6) is a new member of the vitamin K-dependent proteins related to protein $S$, a negative coregulator in the blood coagulation cascade. Mol Cell Biol 13: 4976-4985, 1993.

7. Schneider C, King RM and Philipson L: Genes specifically expressed at growth arrest of mammalian cells. Cell 54: 787-793, 1988.

8. Goruppi S, Ruaro E and Schneider C: Gas6, the ligand of Axl tyrosine kinase receptor, has mitogenic and survival activities for serum starved NIH3T3 fibroblasts. Oncogene 12: 471-480, 1996.

9. Berclaz G, Altermatt HJ, Rohrbach V, Kieffer I, Dreher E and Andres AC: Estrogen dependent expression of the receptor tyrosine kinase axl in normal and malignant human breast. Ann Oncol 12: 819-824, 2001.

10. Craven RJ, Xu LH, Weiner TM, Fridell YW, Dent GA, Srivastava S, Varnum B, Liu ET and Cance WG: Receptor tyrosine kinases expressed in metastatic colon cancer. Int $\mathrm{J}$ Cancer 60: 791-797, 1995.

11. Hutterer M, Knyazev P, Abate A, Reschke M, Maier H, Stefanova N, Knyazeva T, Barbieri V, Reindl M, Muigg A, et al: Axl and growth arrest-specific gene 6 are frequently overexpressed in human gliomas and predict poor prognosis in patients with glioblastoma multiforme. Clin Cancer Res 14: 130-138, 2008.

12. Quong RY, Bickford ST, Ing YL, Terman B, Herlyn M and Lassam NJ: Protein kinases in normal and transformed melanocytes. Melanoma Res 4: 313-319, 1994.

13. Sawabu T, Seno H, Kawashima T, Fukuda A, Uenoyama Y, Kawada M, Kanda N, Sekikawa A, Fukui H, Yanagita M, et al: Growth arrest-specific gene 6 and Axl signaling enhances gastric cancer cell survival via Akt pathway. Mol Carcinog 46: 155-164, 2007.

14. Shieh YS, Lai CY, Kao YR, Shiah SG, Chu YW, Lee HS and Wu CW: Expression of axl in lung adenocarcinoma and correlation with tumor progression. Neoplasia 7: 1058-1064, 2005.

15. Brand-Saberi B, Müller TS, Wilting J, Christ B and Birchmeier C: Scatter factor/hepatocyte growth factor (SF/HGF) induces emigration of myogenic cells at interlimb level in vivo. Dev Biol 179: 303-308, 1996.

16. Hattori S, Kikuchi E, Kosaka T, Miyazaki Y, Tanaka N, Miyajima A, Mikami S and Oya M: Relationship between increased expression of the Axl/Gas6 signal cascade and prognosis of patients with upper tract urothelial carcinoma. Ann Surg Oncol 23: 663-670, 2016.

17. Reichl P, Dengler M, van Zijl F, Huber H, Führlinger G, Reichel C, Sieghart W, Peck-Radosavljevic M, Grubinger M and Mikulits W: Axl activates autocrine transforming growth factor- $\beta$ signaling in hepatocellular carcinoma. Hepatology 61: 930-941, 2015.

18. Brand TM, Iida M, Stein AP, Corrigan KL, Braverman CM, Coan JP, Pearson HE, Bahrar H, Fowler TL, Bednarz BP, et al: AXL is a logical molecular target in head and neck squamous cell carcinoma. Clin Cancer Res 21: 2601-2612, 2015.

19. Dunne PD, McArt DG, Blayney JK, Kalimutho M, Greer S, Wang T, Srivastava S, Ong CW, Arthur K, Loughrey M, et al: AXL is a key regulator of inherent and chemotherapy-induced invasion and predicts a poor clinical outcome in early-stage colon cancer. Clin Cancer Res 20: 164-175, 2014.

20. Lee HJ, Jeng YM, Chen YL, Chung L and Yuan RH: Gas6/Axl pathway promotes tumor invasion through the transcriptional activation of Slug in hepatocellular carcinoma. Carcinogenesis 35: 769-775, 2014.

21. Debruyne DN, Bhatnagar N, Sharma B, Luther W, Moore NF, Cheung NK, Gray NS and George RE: ALK inhibitor resistance in ALK(F1174L)-driven neuroblastoma is associated with AXL activation and induction of EMT. Oncogene 35: 3681-3691, 2016.

22. Giles KM, Kalinowski FC, Candy PA, Epis MR, Zhang PM, Redfern AD, Stuart LM, Goodall GJ and Leedman PJ: Axl mediates acquired resistance of head and neck cancer cells to the epidermal growth factor receptor inhibitor erlotinib. Mol Cancer Ther 12: 2541-2558, 2013.

23. Zhang Z, Lee JC, Lin L, Olivas V, Au V, LaFramboise T, Abdel-Rahman M, Wang X, Levine AD, Rho JK, et al: Activation of the AXL kinase causes resistance to EGFR-targeted therapy in lung cancer. Nat Genet 44: 852-860, 2012. 
24. Müller J, Krijgsman O, Tsoi J, Robert L, Hugo W, Song C, Kong X, Possik PA, Cornelissen-Steijger PD, Geukes Foppen MH, et al: Low MITF/AXL ratio predicts early resistance to multiple targeted drugs in melanoma. Nat Commun 5: 5712, 2014.

25. Heymann S, Koudrova M, Arnold H, Köster M and Braun T: Regulation and function of SF/HGF during migration of limb muscle precursor cells in chicken. Dev Biol 180: 566-578, 1996.

26. Borowiak M, Garratt AN, Wüstefeld T, Strehle M, Trautwein C and Birchmeier C: Met provides essential signals for liver regeneration. Proc Natl Acad Sci USA 101: 10608-10613, 2004.

27. Huh CG, Factor VM, Sánchez A, Uchida K, Conner EA and Thorgeirsson SS: Hepatocyte growth factor/c-met signaling pathway is required for efficient liver regeneration and repair. Proc Natl Acad Sci USA 101: 4477-4482, 2004.

28. Di Renzo MF, Poulsom R, Olivero M, Comoglio PM and Lemoine NR: Expression of the Met/hepatocyte growth factor receptor in human pancreatic cancer. Cancer Res 55: 1129-1138, 1995.

29. Lengyel E, Prechtel D, Resau JH, Gauger K, Welk A Lindemann K, Salanti G, Richter T, Knudsen B, Vande Woude GF, et al: C-Met overexpression in node-positive breast cancer identifies patients with poor clinical outcome independent of Her2/neu. Int J Cancer 113: 678-682, 2005.

30. Liu C, Park M and Tsao MS: Overexpression of c-met protooncogene but not epidermal growth factor receptor or c-erbB-2 in primary human colorectal carcinomas. Oncogene 7: 181-185, 1992.

31. Ramirez R, Hsu D, Patel A, Fenton C, Dinauer C, Tuttle RM and Francis GL: Over-expression of hepatocyte growth factor/scatter factor $(\mathrm{HGF} / \mathrm{SF}$ ) and the $\mathrm{HGF} / \mathrm{SF}$ receptor (cMET) are associated with a high risk of metastasis and recurrence for children and young adults with papillary thyroid carcinoma. Clin Endocrinol (Oxf) 53: 635-644, 2000

32. Rho JK, Choi YJ, Kim SY, Kim TW, Choi EK, Yoon SJ, Park BM, Park E, Bae JH, Choi CM, et al: MET and AXL inhibitor NPS-1034 exerts efficacy against lung cancer cells resistant to EGFR kinase inhibitors because of MET or AXL activation. Cancer Res 74: 253-262, 2014.

33. Tokunou M, Niki T, Eguchi K, Iba S, Tsuda H, Yamada T, Matsuno Y, Kondo $\mathrm{H}$, Saitoh Y, Imamura $\mathrm{H}$, et al: c-MET expression in myofibroblasts: Role in autocrine activation and prognostic significance in lung adenocarcinoma. Am J Pathol 158: 1451-1463, 2001.

34. Tsao MS, Liu N, Chen JR, Pappas J, Ho J, To C, Viallet J, Park M and Zhu H: Differential expression of Met/hepatocyte growth factor receptor in subtypes of non-small cell lung cancers. Lung Cancer 20: 1-16, 1998.

35. Ma PC, Jagadeeswaran R, Jagadeesh S, Tretiakova MS, Nallasura V, Fox EA, Hansen M, Schaefer E, Naoki K, Lader A et al: Functional expression and mutations of c-Met and its therapeutic inhibition with SU11274 and small interfering RNA in non-small cell lung cancer. Cancer Res 65: 1479-1488, 2005.
36. Wimmel A, Glitz D, Kraus A, Roeder J and Schuermann M: Axl receptor tyrosine kinase expression in human lung cancer cell lines correlates with cellular adhesion. Eur J Cancer 37: 2264-2274, 2001

37. Salian-Mehta S, Xu M and Wierman ME: AXL and MET crosstalk to promote gonadotropin releasing hormone $(\mathrm{GnRH})$ neuronal cell migration and survival. Mol Cell Endocrinol 374: 92-100, 2013

38. Kim HR, Kim WS, Choi YJ, Choi CM, Rho JK and Lee JC Epithelial-mesenchymal transition leads to crizotinib resistance in H2228 lung cancer cells with EML4-ALK translocation. Mol Oncol 7: 1093-1102, 2013

39. Li Y, Ye X, Tan C, Hongo JA, Zha J, Liu J, Kallop D, Ludlam MJ and Pei L: Axl as a potential therapeutic target in cancer: Role of $\mathrm{Axl}$ in tumor growth, metastasis and angiogenesis. Oncogene 28: 3442-3455, 2009.

40. Organ SL and Tsao MS: An overview of the c-MET signaling pathway. Ther Adv Med Oncol 3 (Suppl): S7-S19, 2011.

41. Sierra JR and Tsao MS: c-MET as a potential therapeutic target and biomarker in cancer. Ther Adv Med Oncol 3 (Suppl): S21-S35, 2011

42. Gujral TS, Karp RL, Finski A, Chan M, Schwartz PE, MacBeath $\mathrm{G}$ and Sorger P: Profiling phospho-signaling networks in breast cancer using reverse-phase protein arrays. Oncogene 32: 3470-3476, 2013.

43. Folkman J: Tumor angiogenesis: Therapeutic implications. N Engl J Med 285: 1182-1186, 1971.

44. Freudlsperger C, Alexander D, Reinert S and Hoffmann J: Prognostic value of c-Met expression in oral squamous cell carcinoma. Exp Ther Med 1: 69-72, 2010.

45. Gisterek I, Lata E, Halon A, Matkowski R, Szelachowska J, Biecek P and Kornafel J: Prognostic role of c-met expression in breast cancer patients. Rep Pract Oncol Radiother 16: 173-177, 2011.

46. Ishikawa M, Sonobe M, Nakayama E, Kobayashi M, Kikuchi R, Kitamura J, Imamura $\mathrm{N}$ and Date $\mathrm{H}$ : Higher expression of receptor tyrosine kinase $\mathrm{Axl}$, and differential expression of its ligand, Gas6, predict poor survival in lung adenocarcinoma patients. Ann Surg Oncol 20 (Suppl 3): S467-S476, 2013.

47. Lee CH, Yen CY, Liu SY, Chen CK, Chiang CF, Shiah SG, Chen PH and Shieh YS: Axl is a prognostic marker in oral squamous cell carcinoma. Ann Surg Oncol 19 (Suppl 3): S500-S508, 2012.

48. Pinato DJ, Mauri FA, Lloyd T, Vaira V, Casadio C, Boldorini RL and Sharma R: The expression of Axl receptor tyrosine kinase influences the tumour phenotype and clinical outcome of patients with malignant pleural mesothelioma. Br J Cancer 108: 621-628, 2013. 